\title{
Article \\ Effect of Sulfurization Time on the Physical Properties of Tin (II) Monosulfide Thin Films
}

\author{
Vasudeva Reddy Minnam Reddy ${ }^{1,2}$, Sreedevi Gedi ${ }^{1,2}$, Rutuja U. Amate ${ }^{1}$, K. T. Ramakrishna Reddy ${ }^{2, *}$, \\ Woo Kyoung Kim ${ }^{1, *}$ and Chinho Park ${ }^{1, *}$
}

1 School of Chemical Engineering, Yeungnam University, Gyeongsan 38541, Korea; drmvasudr9@gmail.com (V.R.M.R.); drsrvi9@gmail.com (S.G.); rutu.nanoworld@gmail.com (R.U.A.)

2 Solar Energy Laboratory, Department of Physics, Sri Venkateswasra University, Tirupati 517102, India

* Correspondence: ktrkreddy@gmail.com (K.T.R.R.); wkim@ynu.ac.kr (W.K.K.); chpark@ynu.ac.kr (C.P.)

Citation: Minnam Reddy, V.R.; Gedi, S.; Amate, R.U.; Ramakrishna Reddy, K.T.; Kim, W.K.; Park, C. Effect of Sulfurization Time on the Physical Properties of Tin (II) Monosulfide Thin Films. Crystals 2021, 11, 802. https://doi.org/10.3390/ cryst11070802

Academic Editor: Alberto Girlando

Received: 10 May 2021

Accepted: 7 July 2021

Published: 9 July 2021

Publisher's Note: MDPI stays neutral with regard to jurisdictional claims in published maps and institutional affiliations.

Copyright: (c) 2021 by the authors. Licensee MDPI, Basel, Switzerland. This article is an open access article distributed under the terms and conditions of the Creative Commons Attribution (CC BY) license (https:// creativecommons.org/licenses/by/ $4.0 /)$

\begin{abstract}
Tin (II) monosulfide (SnS) films were prepared via sulfurization using sputtered Sn precursors of the tin metal layers in the presence of elemental sulfur vapor as a function of sulfurization time $\left(t_{s}\right)$ in the range of 30-180 min while keeping other parameters constant. The properties of these sulfurized layers were examined through suitable characterization techniques. The diffraction patterns exhibited various planes with the orientations (110), (120), (021), (101), (111), (211), (131), (210), (141), (002), (112), (122), and (042) corresponding to orthorhombic SnS at $t_{\mathrm{s}} \leq 90 \mathrm{~min}$. However, for $t_{s} \geq 120 \mathrm{~min}$, the diffraction patterns showed a single (111) plane and enhanced the intensity of the peak with the increase of $t_{s}$ up to $150 \mathrm{~min}$; with further increase of time, the peak intensity was found to decrease. The Raman spectra of films sulfurized at various $t_{\mathrm{s}}$ showed modes at 95, 162, 189, 219 , and $284 \mathrm{~cm}^{-1}$ for times were lower than $120 \mathrm{~min}$ and 95,189 , and $219 \mathrm{~cm}^{-1}$ for $\mathrm{t}_{\mathrm{s}} \geq 120 \mathrm{~min}$, related to SnS. In the transmittance spectra of the sulfurized films, it is clear that the film grown at $t_{s}=30 \mathrm{~min}$ had higher transmittance, and with the increase of $t_{s}$ to $120 \mathrm{~min}$, transmittance was decreased. For further extension of $t_{\mathrm{s}}$ to $150 \mathrm{~min}$, a sharp falling of the absorption edge was observed.
\end{abstract}

Keywords: tin (II) monosulfide; sulfurization; solar cells

\section{Introduction}

Second-generation photovoltaic thin film technology (a-Si, CdTe, and $\left.\mathrm{Cu}(\mathrm{In}, \mathrm{Ga}) \mathrm{S}_{2}\right)$ is universally recognized as reducing production costs and the weight of devices [1]. However, utilization of a toxic, expensive, and high-temperature process, as well as a laborious process, prevents further devolvement of photovoltaic thin film technology [2]. Therefore, a non-toxic, low-cost, and simple (low temperature and easy) process is required for further development.

Tin sulfide (SnS) contains an abundant, cheap, and non-toxic elements. Further, $\mathrm{SnS}$ thin films have shown direct optical transition with an optical bandgap of about $1.3 \mathrm{eV}$ and p-type electrical conductivity [3-7]. Therefore, $\mathrm{SnS}$ is a promising material for thin film photovoltaics. Normally, tin (II) monosulfide films have been deposited by various methods, including chemical bath deposition, spin-coating, spray pyrolysis, pulsed electro-deposition, evaporation, and sulfurization, among others [5,8-12]. Among these methods, sulfurization of the tin metal layer is a simple (low temperature and easy) process, and films can be deposited over a large area. During the sulfurization of tin metal layers, secondary phases such as $\mathrm{SnS}_{2}$ and $\mathrm{Sn}_{2} \mathrm{~S}_{3}$ could be formed owing to insufficient sulfurization temperature and sulfurization time as well as sulfur partial pressure. These secondary phases result in the development of leakage currents in SnS devices [13]. Additionally, n-type $\mathrm{SnS}_{2}$ in p-type $\mathrm{SnS}$ degrade the characteristics of the p-n diode [14]. Owing to the intergrowth of many crystal types, the crystal lattice of $\mathrm{SnS}$ is normally non-ideal and includes defects and imperfections $[15,16]$. As a result, the relationship between the physical properties and crystal lattice structure of tin (II) 
monosulfide is critical as the method of sulfurization and sulfurization conditions have an effect on them.

The impact of sulfurization temperature on the physical properties of tin (II) monosulfide thin films was investigated systematically and thoroughly $[3,16]$. However, the effect of sulfurization time and sulfur partial pressure on the physical properties of tin (II) monosulfide thin films is limited. Thus, if the sulfurization temperature was fixed at a constant value, then the influencing growth parameter is the sulfurization time, which determines the required time to occupy their equilibrium positions of an ordered state of atoms. Hence, for a better understanding of the effect of sulfurization time on the properties of the SnS absorber layer, sulfurization metallic tin precursors were studied as a function of sulfurization time for previously optimized constant sulfurization temperature of $350{ }^{\circ} \mathrm{C}$ using a closed chamber furnace in an environment of elemental sulfur vapor. Further, the sulfurization time determines the amount of sulfur diffusion into the metallic tin layers. Sulfurization for a long time leads to re-evaporation of sulfur on the surface of the layer without new layers being formed. On the other hand, if the sulfurization time is not long enough, then the tin monosulfide film will be too thin, and sulfur may not diffuse into the metallic tin after the sulfurization process. Hence, optimization of sulfurization time was determined based on the analysis of different phases present; the surface topography; the distribution of the elements in the layers; and the structural, optical, and electrical properties using X-ray photoelectron spectroscopy (XPS), X-ray diffractometer (XRD), Raman spectrometer, atomic force microscope (AFM), and UV/Vis-NIR spectrophotometer.

\section{Experimental Details}

For the deposition of tin (II) monosulfide films on soda-lime glass (SLG), direct current magnetron sputtering (VRSU048) and sulfurization setup [3] were used. First, the base pressure of $1 \times 10^{-6}$ Torr was achieved in the chamber of a sputtering system using turbomolecular and rotary pumps. By allowing the argon gas, working pressure of $5 \times 10^{-3}$ Torr was achieved in the chamber of a sputtering system to deposit the metallic tin precursor layers on soda-lime glass. Tin precursor layers were deposited with the tin target (4N, Kurt J. Lesker, UK). The deposited tin precursor layers and sulfur flacks were loaded in a graphite box, which was kept in the sulfurization chamber, as shown in Figure 1. A rotary pump is used to achieve $1 \times 10^{-3}$ Torr. Next, sulfurization was performed in the period of 30-180 min for a fixed sulfurization temperature of $350{ }^{\circ} \mathrm{C}$. The deposition and characterization details were provided in our previous work $[3,5,17]$.

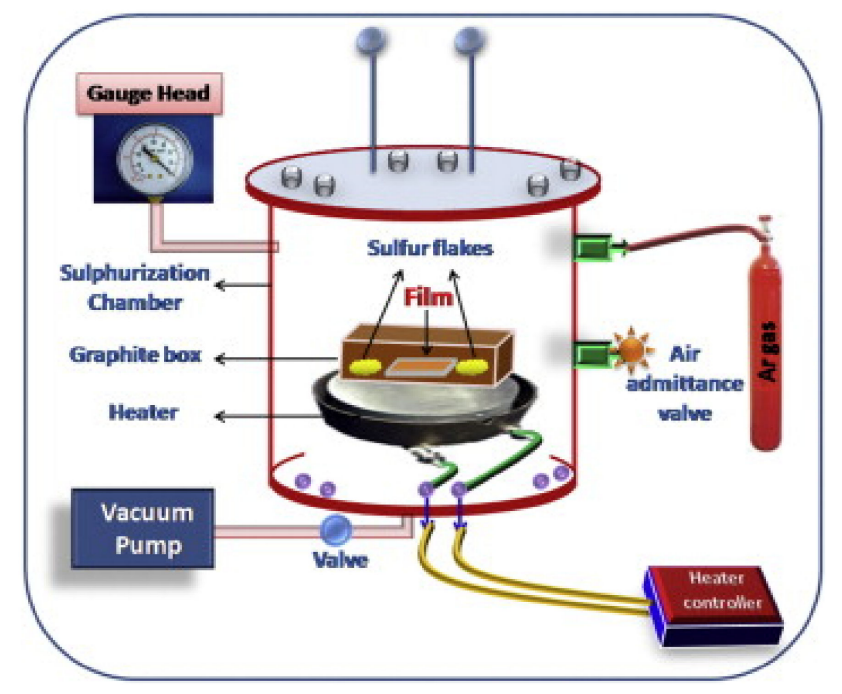

Figure 1. Experimental setup of the sulfurization (reprinted with permission from [3]; Copyright@ 2015 Elsevier Ltd.). 


\section{Results and Discussion}

\subsection{XPS Analysis}

The presence of different elements, their electronic binding energies, and the ionization states of elements in SnS films were investigated by X-ray photoelectron spectroscopy (XPS). The complete scan X-ray photoelectron spectroscopy results are shown in Figure 2 for SnS film sulfurized at a typical time period of $150 \mathrm{~min}$. The binding energy values obtained in the X-ray photoelectron spectroscopy analysis were corrected by referencing the $\mathrm{C} 1 \mathrm{~s}$ peak to $284.80 \mathrm{eV}$. The survey X-ray photoelectron spectroscopy of the samples revealed that the presence of tin, sulfur, oxygen, and carbon components. The binding energy (BE) values of the peaks at $485.8 \mathrm{eV}$ and $161.2 \mathrm{eV}$ were assigned to $\mathrm{Sn} 3 \mathrm{~d}_{5 / 2} \mathrm{of} \mathrm{Sn}^{+2}$ and $\mathrm{S}^{2} \mathrm{p}_{3 / 2}$ of $\mathrm{S}^{-2}$ in tin (II) monosulfide, respectively [3,18]. Further, $\mathrm{Sn}^{0}$ (at $484.9 \mathrm{eV}$ ) and $\mathrm{Sn}^{+4}$ (at $487.3 \mathrm{eV}$ ) were not observed in the $\mathrm{Sn}_{3} \mathrm{~d}_{5 / 2}$ peak, demonstrating the formation of single-phase tin (II) monosulfide films [19-21]. From the XPS analysis, it is confirmed that the tin precursor layers were converted into single-phase tin (II) monosulfide films merely in the entire sulfurization time period. The composition analysis indicated a slightly sulfur-rich composition at lower sulfurization time periods, and with an increase of time period, the composition approaches stoichiometry at $150 \mathrm{~min}$. Thus, the single-phase SnS films had elemental compositions of $\mathrm{Sn}=50.2 \mathrm{at} \%$ and $\mathrm{S}=49.8 \mathrm{at} \%$.

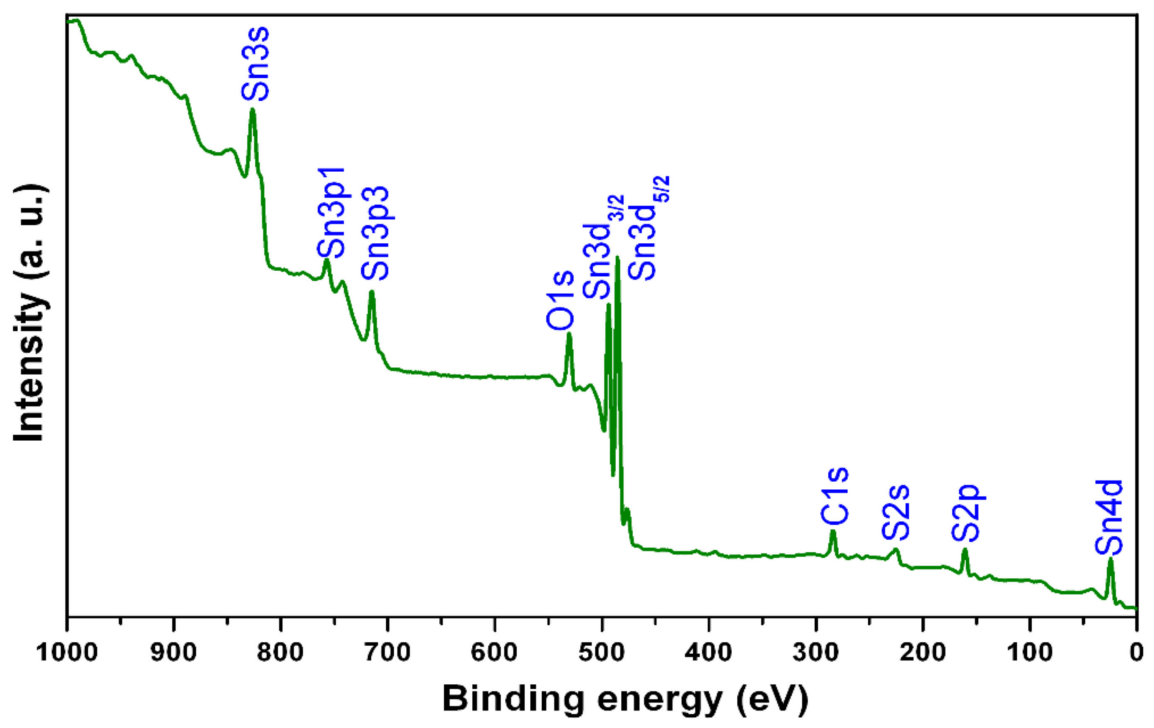

Figure 2. X-ray photoelectron spectroscopy (XPS) wide scan spectrum of film sulfurized at sulfurization time of $150 \mathrm{~min}$.

\subsection{XRD Analysis}

X-ray diffraction (XRD) patterns of tin (II) monosulfide films for various sulfurization durations are shown in Figure 3. It is noticed that all the sulfurized SnS films were polycrystalline in nature. The sulfurized SnS films exhibited an orthorhombic structure. The diffraction peaks present at $2 \theta$ values, $22.18^{\circ}, 26.02^{\circ}, 26.84^{\circ}, 29.92^{\circ}, 31.50^{\circ}, 31.98^{\circ}$, $33.82^{\circ}, 38.74^{\circ}, 42.62^{\circ}, 44.94^{\circ}, 45.02^{\circ}, 48.06^{\circ}, 52.02^{\circ}, 54.32^{\circ}$, and $57.46^{\circ}$, can be assigned to the orientations (110), (120), (021), (101), (111), (211), (131), (210), (141), (002), (112), (122), and (042), respectively, of orthorhombic SnS and the data obtained matched well with the standard XRD pattern of SnS (JCPDS: 39-0354 ). The peak intensity and sharpness of (111) orientation increased with the prolonging of $t_{s}$ up to $150 \mathrm{~min}$, and with a further increase of time, the peak intensity decreased. This indicates that the crystallinity of the grown layers was increased with the prolonging of $t_{s}$ up to $150 \mathrm{~min}$, and thereafter, it decreased. The spectra did not show peaks corresponding to other binary tin sulfide phases, namely $\mathrm{SnS}_{2}$ and $\mathrm{Sn}_{2} \mathrm{~S}_{3}$. From this study, it is concluded that the films were grown exhibited pure $\mathrm{SnS}$ phase at all sulfurization times without any secondary phases. The 
single phase obtained in the present study might be due to the formation of SnS films at the previously optimized sulfurization temperature $\left(350^{\circ} \mathrm{C}\right)$. Jiang et al. [22] also reported the growth of SnS films at different sulfurization times $(15,30,45,60 \mathrm{~min})$ using a sulfurization temperature of $220^{\circ} \mathrm{C}$ by a two-stage process. However, these films do not exhibit pure SnS phase for all sulfurization time periods, which might be because of a lack of optimization of sulfurization temperature and other parameters. In the literature [23], the films deposited by vacuum techniques showed the preferred orientation of the (111) and (040) planes. In the present case, it is found that, for smaller sulfurization time periods, the films exhibited both (111) and (040) orientations. However, with the extended $t_{s}$, the intensity of the (040) peak diminished and disappeared after $60 \mathrm{~min}$, whereas the intensity of the (111) peak increased continuously up to a sulfurization time of $150 \mathrm{~min}$, and then decreased slightly.

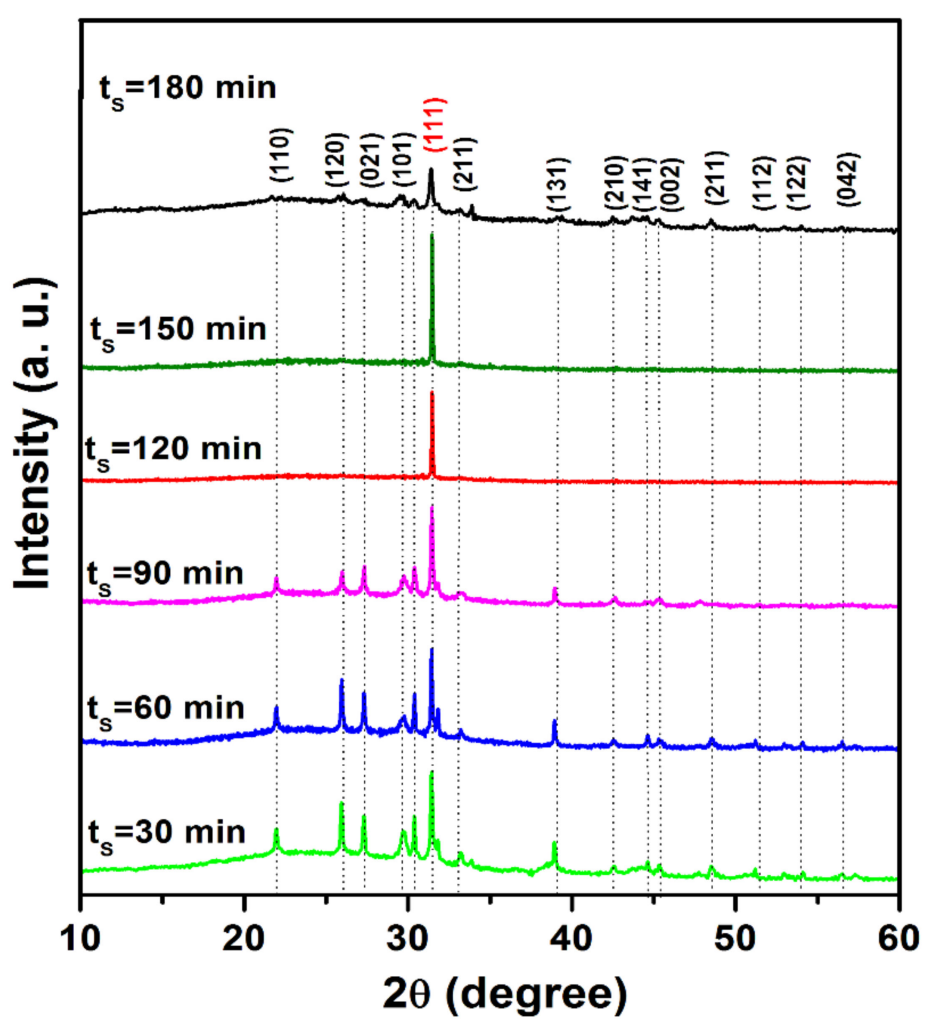

Figure 3. X-ray diffraction (XRD) patterns of metallic tin precursor films sulfurized at various time periods.

The observed change of tin (II) monosulfide crystal orientation in the present work is due to the surface energies of tin (II) monosulfide crystal planes, which have different energies. Further, tin (II) monosulfide is a layered semiconductor material with the layer plane perpendicular to the $b$ crystallographic axis; the crystal plane of $\{010\}$ has much lower surface energy than the $\{100\}$ and $\{001\}$ crystal plane at the surface boundary. When tin (II) monosulfide starts to nucleate on the substrate surface, the $\{010\}$ crystal plane would be preferred to align parallel to the substrate to minimize the surface energy. Once the film grows thicker, the surface areas (plane defects) are mainly from the grain boundaries within the film rather than from the top surface. Thus, the minimum surface energy is to have a $\{010\}$ plane parallel to the grain boundaries, which is perpendicular to the substrate surface owing to the nature of the columnar structure in this case [23]. The preferential orientation of tin (II) monosulfide films is regulated by nucleation, which depends on film thickness, substrate temperature, deposition time, type of substrates, and film preparation method as the process. A similar kind of behavior has also been observed in the earlier studies made by Tanusevski et al. [24] and Cheng et al. [25] in the literature. 
The crystallite size of tin (II) monosulfide films is evaluated from the full width at half maxima (FWHM) of the most predominant orientation in the XRD patterns of tin (II) monosulfide films, the (111) plane, using the Scherrer formula [26] given below.

$$
D=\frac{0.94 \lambda}{\beta \cos (\theta)}
$$

where $\lambda$ is the radiation wavelength, $\beta$ is the corrected FWHM of the main X-ray diffraction peak, and $\theta$ is the XRD peak position. Figure 4 shows the change of crystallite size with sulfurization time. It can be seen that as $t_{s}$ is prolonged up to $150 \mathrm{~min}$, the crystallite size increased from $80 \mathrm{~nm}$ to $320 \mathrm{~nm}$, and then decreased. This is mainly because, with the consistent increase of time $(150 \mathrm{~min})$, the recrystallization might take place to improve the crystallite size.

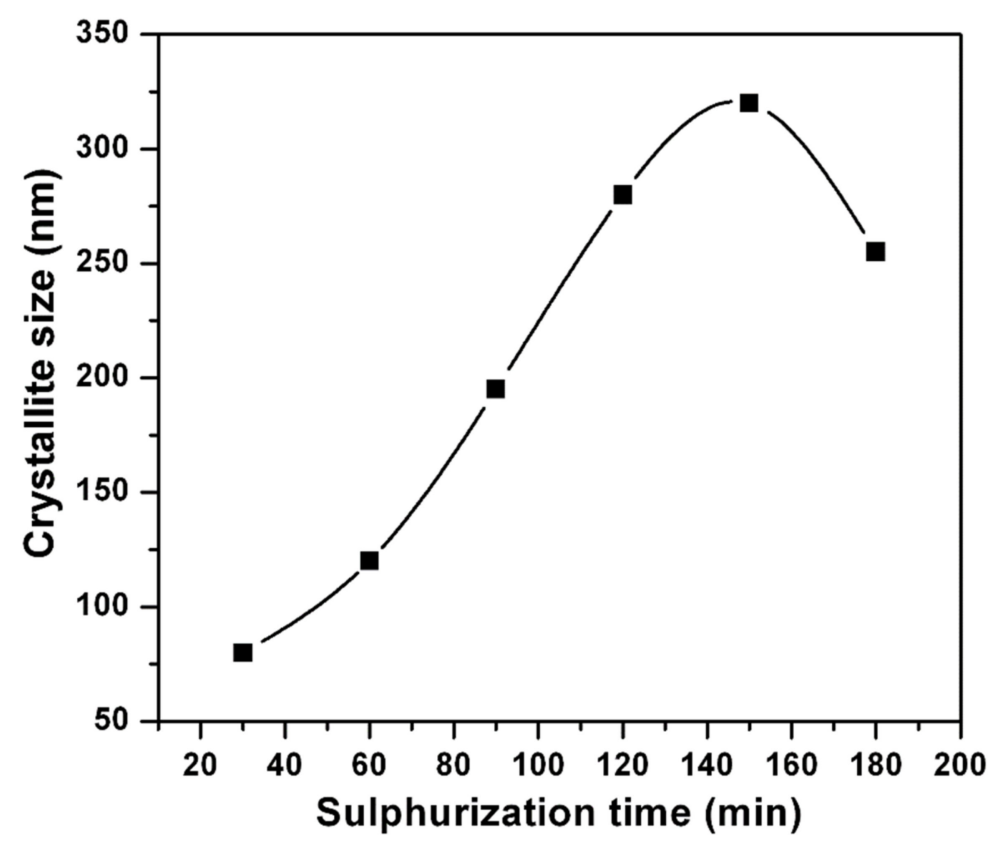

Figure 4. Variation of crystallite size with sulfurization time.

\subsection{Raman Studies}

Generally, it is difficult to differentiate the $S n S, S n S_{2}$, and $S_{2} S_{3}$ using XRD analysis if the films contain a small quantity of these secondary tin sulfide phases. Particularly, differentiation of $\mathrm{SnS}$ and $\mathrm{Sn}_{2} \mathrm{~S}_{3}$ peaks is a great task as the Bragg angles for both peaks fall in the range of $2 \theta=31-32^{\circ}$ [16]. In this situation, Raman analysis is a straightforward technique to identify the phase purity of $\mathrm{SnS}$. Further, it is also proved to be an important tool for the identification of minor impurities in the case of $\mathrm{Cu}_{2} \mathrm{ZnSnS}_{4}$ and $\mathrm{Cu}_{2} \mathrm{SnS}_{3}$. Figure 5 shows the Raman spectra of sulfurized films at different sulfurization times, and the spectra were recorded at room temperature. Vibrational modes of sulfurized films were detected at $95 \mathrm{~cm}^{-1}, 162 \mathrm{~cm}^{-1}, 189 \mathrm{~cm}^{-1}, 219 \mathrm{~cm}^{-1}$, and $284 \mathrm{~cm}^{-1}$ for lower than $120 \mathrm{~min}$ and $95 \mathrm{~cm}^{-1}, 189 \mathrm{~cm}^{-1}$, and $219 \mathrm{~cm}^{-1}$ for $\geq 120 \mathrm{~min}$, related to tin (II) monosulfide. Raman vibrational modes at $95 \mathrm{~cm}^{-1}, 189 \mathrm{~cm}^{-1}$, and $219 \mathrm{~cm}^{-1}$ belong to the $A_{g}$ mode of tin (II) monosulfide films, and the other modes at 162 and $284 \mathrm{~cm}^{-1}$ belong to the $\mathrm{B}_{2 \mathrm{~g}}$ mode of tin (II) monosulfide films. According to the previous reports, the appearance of $\mathrm{A}_{\mathrm{g}}$ and $\mathrm{B}_{3 \mathrm{~g}}$ modes of tin (II) monosulfide corresponded to the incident; scattered directions parallel to one of $a, b$, and $c$ axis of tin (II) monosulfide; and, in the present case, it is the b-axis. Crystal clear $\mathrm{B}_{1 \mathrm{~g}}$ and $\mathrm{B}_{2 \mathrm{~g}}$ modes of tin (II) monosulfide were not detected; those appeared when the incident scattered direction was parallel to the a-axis and c-axis of tin (II) monosulfide, respectively [27]. In general, owing to dominant electrostatic field interaction in tin (II) monosulfide, the phonons of tin (II) monosulfide exhibit nearly pure 
longitudinal or transverse character. Mostly, there is no merging that takes place between the transverse and the longitudinal atomic vibrations in tin (II) monosulfide. Under certain propagation and polarization conditions, phonons of combined symmetry character arise and can be detected in the Raman spectra. In the present investigation, the longitudinal optical modes are $162 \mathrm{~cm}^{-1}, 189 \mathrm{~cm}^{-1}, 219 \mathrm{~cm}^{-1}$, and $284 \mathrm{~cm}^{-1}$, while the transverse ( $\mathrm{TO}=3$ ) optical mode is $95 \mathrm{~cm}^{-1}$ [27]. The transverse mode is observed presumably due to the backscattering geometry, which is not strictly backscattering. The results of the present work agree with the previously reported data at vibrational modes of $95 \mathrm{~cm}^{-1}$, $162 \mathrm{~cm}^{-1}, 189 \mathrm{~cm}^{-1}, 219 \mathrm{~cm}^{-1}$, and $284 \mathrm{~cm}^{-1}$ for films grown on the amorphous substrate. Further, the intensity of Raman vibrational modes for tin (II) monosulfide films at different sulfurization times is high and sharper with increasing time, indicating the quality of the tin (II) monosulfide films. Furthermore, no significant peak shift and broadening are observed in the Raman spectra, indicating that the films are free from strain. This result confirmed that the films grown at different sulfurization times are single-phase tin (II) monosulfide without the presence of additional phases such as $\mathrm{SnS}_{2}\left(312 \mathrm{~cm}^{-1}\right)$ and $\mathrm{Sn}_{2} \mathrm{~S}_{3}$ $\left(304 \mathrm{~cm}^{-1}\right)[19,28]$.

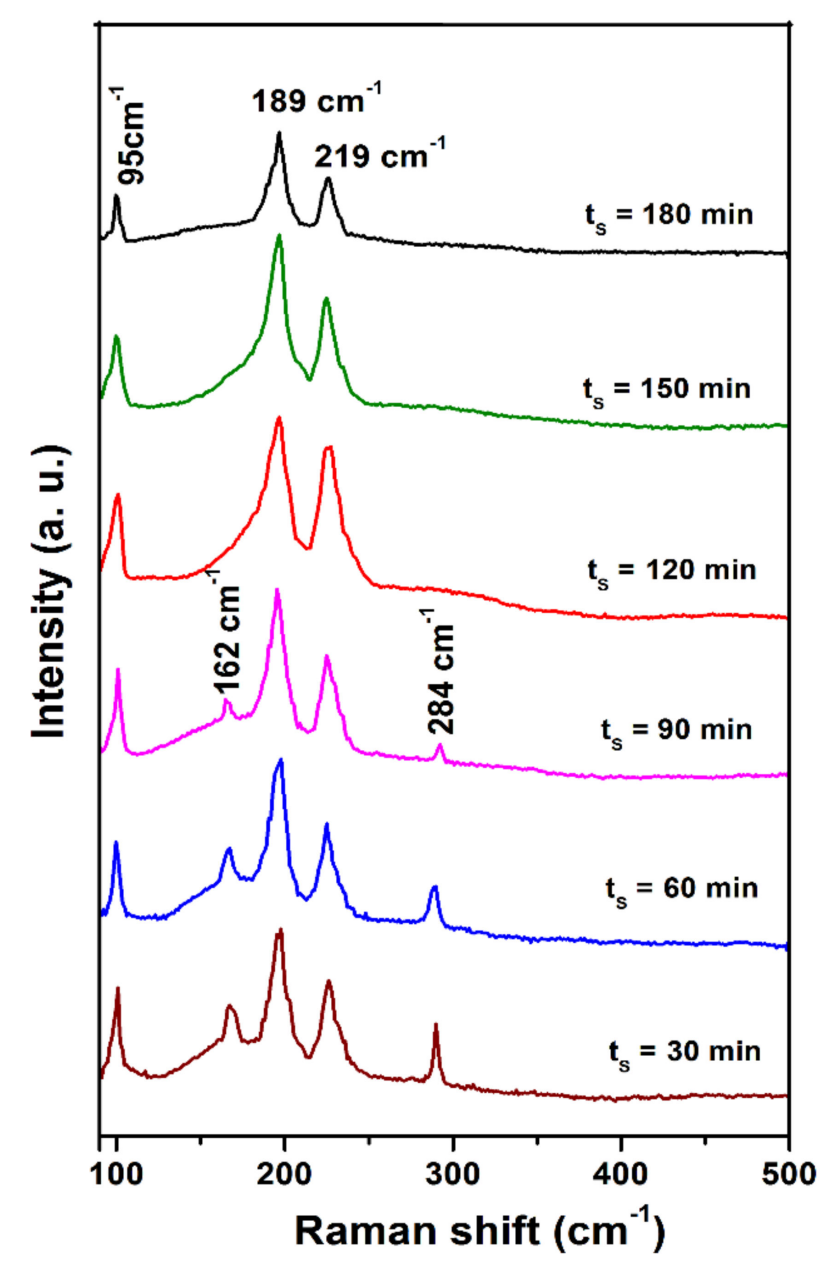

Figure 5. Raman spectra of sulfurized films at various sulfurization durations.

\subsection{AFM Studies}

Figure 6 shows the surface topology of tin (II) monosulfide films at various sulfurization times. The roughness of the tin (II) monosulfide films increased with the prolonging of $t_{s}$, thereby increasing the grain size. The average crystallite size obtained in the XRD results is consistent with AFM studies. The improvement in the crystallinity of the film occurs by the coalescence of the neighboring islands. Further, the films sulfurized at a short sulfurization time had a high surface roughness of $18 \mathrm{~nm}$ that decreased to $5 \mathrm{~nm}$ 
when the sulfurization duration was raised further. The average grain size of the films varied in the range of $80-320 \mathrm{~nm}$, with the change of sulfurization time in the range of 30-180 $\mathrm{min}$. The variation in the surface roughness as a function of sulfurization time can be explained as follows. The availability of time to diffuse sulfur atoms into the tin metal layer and filling of sulfur sites could not occur at lower sulfurization times, resulting in the formation of crystallites with higher surface roughness. The formation of polycrystalline SnS thin film can be explained based on the occurrence of a number of events, which are nucleation, growth, and coalescence of islands. As sulfurization time is prolonged, the adsorbed $S$ atoms possess enough sulfurization time to settle on the substrate surface with the minimum potential energy positions (this is cluster or island formation), and the crystallization is facilitated because of island coalescence (growth) promoted by increased surface and volume diffusion of S, resulting in the development of larger grains.
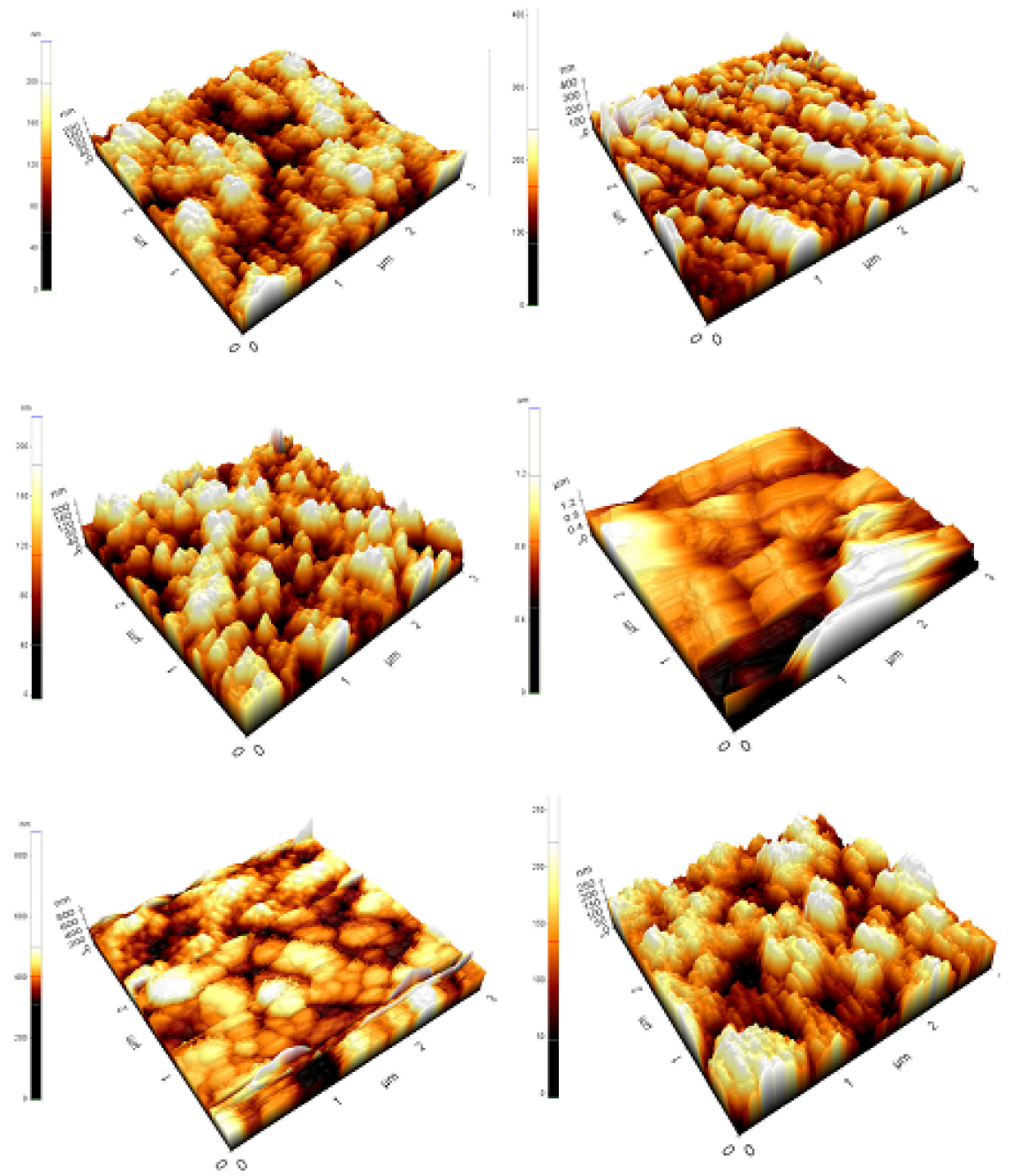

Figure 6. Atomic force microscope (AFM) images of the SnS films sulfurized at different time periods.

\subsection{Optical Studies}

To confirm and evaluate the optical properties such as transmittance, absorption coefficient, and bandgap of the sulfurized films, the UV/Vis-NIR transmittance spectra of all the sulfurized films were experimentally measured. Figure 7 shows the transmittance versus wavelength spectra of the films sulfurized at various $t_{s}$. 


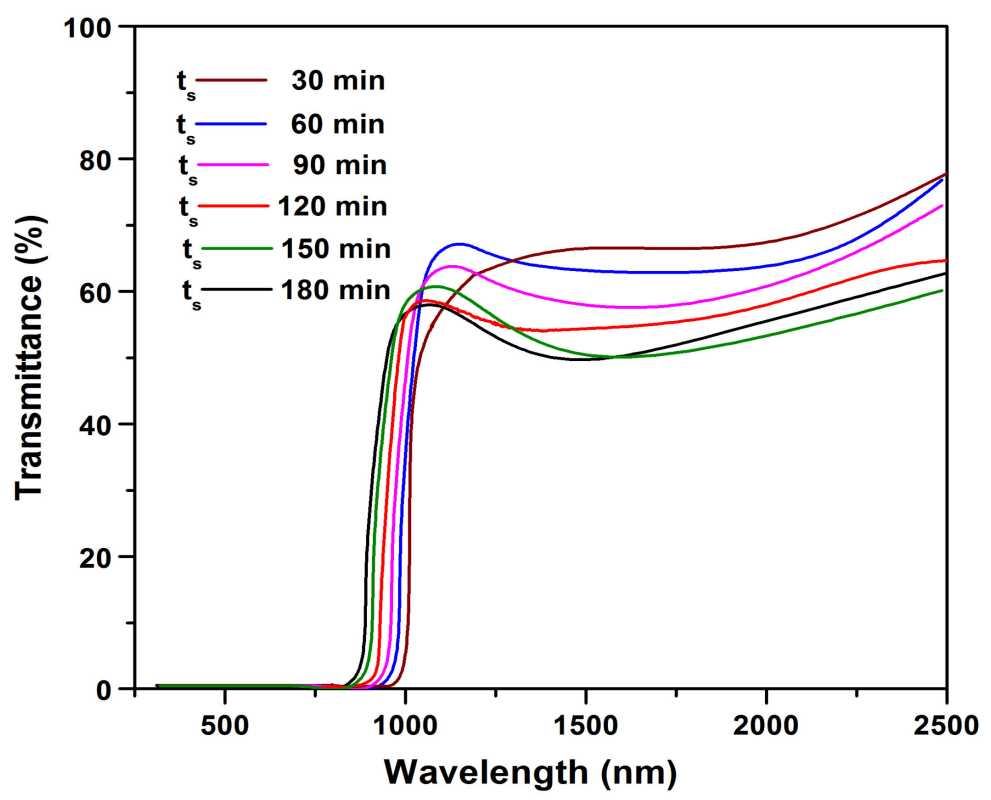

Figure 7. Transmittance versus wavelength spectra of SnS films.

From Figure 7, a significant change in UV/Vis-NIR transmittance can be noticed with the increase of $t_{s}$. The films sulfurized at $30 \mathrm{~min}$ had higher transmittance, and with the increase in $t_{\mathrm{s}}$ to $120 \mathrm{~min}$, the transmittance was found to be decreased, and the absorption edge was blue shifted. With further prolonging the sulfurization time to $150 \mathrm{~min}$, a sharp fall in the fundamental absorption edge was observed. This could be due to the high crystallinity and internal morphology of the sulfurized film.

The absorption coefficient was calculated from the experimentally measured values of transmittance $(\mathrm{T})$ using the following relation [6]:

$$
\alpha=-(1 / t) \ln (1 / T)
$$

where $t$ is the thickness of sulfurized films. The evaluated $\alpha$ was in the order of $10^{4} \mathrm{~cm}^{-1}$, which supports the direct bandgap nature of the material. The bandgap of the samples was determined using the following relation [6]:

$$
\alpha h v=A\left(h v-E_{g}\right)^{x}
$$

The optical bandgap of sulfurized films is obtained by extrapolating the linear part of the curves onto the horizontal axis. Figure 8 shows the plot of $(\alpha h v)^{2}$ versus $h v$ for sulfurized films. As seen from the figure, the bandgap increased with $t_{\mathrm{s}}$. The bandgap of the tin (II) monosulfide films increased with the increase in sulfurization time. This is because of the decrease in defect concentration. From the figure, it was observed that, with increasing sulfurization time of tin (II) monosulfide film, the bandgap increases from $1.25 \mathrm{eV}$ to $1.50 \mathrm{eV}$. This may be because of the change in inhomogeneity and crystallinity of the films. The bandgap of the $\mathrm{SnS}$ film is quite close to the optimum bandgap required for a solar cell. 


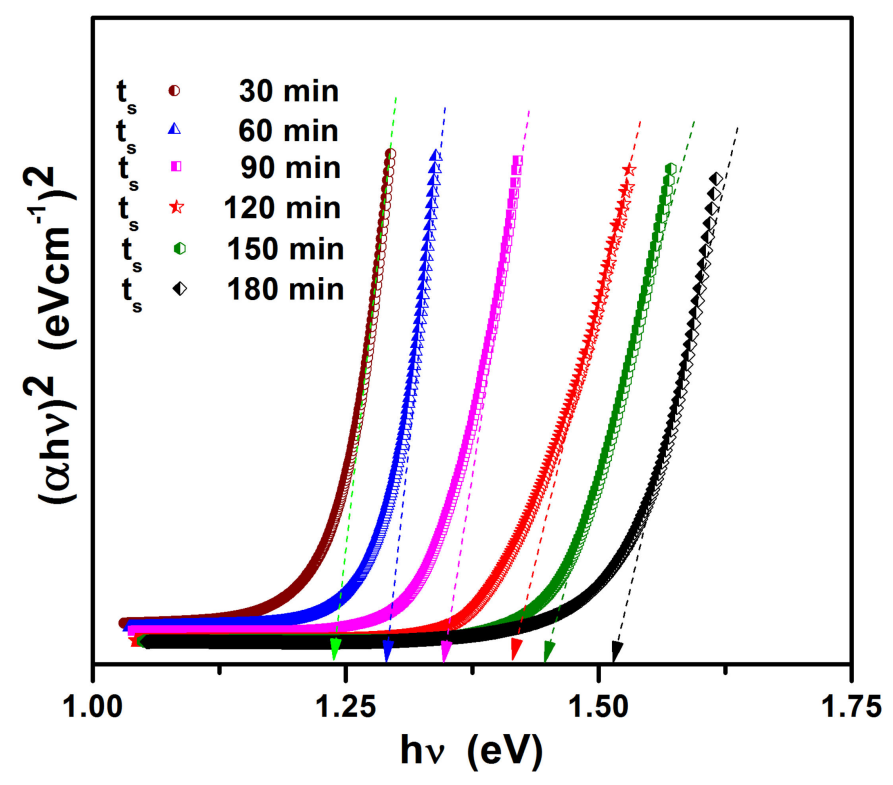

Figure 8. Plots of $(\alpha h v)^{2}$ versus $h v$ for SnS films.

\section{Conclusions}

The SnS films were prepared via a two-stage process using sputtered Sn precursors in the presence of sulfur vapor to study the effect of sulfurization time, which varied in the range of 30-180 $\mathrm{min}$ at an optimized sulfurization temperature of $350{ }^{\circ} \mathrm{C}$. The films grown were characterized using structural, topographical, compositional, and optical properties. The XPS spectrum of sulfurized films showed the presence of tin and sulfur. The XRD results revealed that all the tin (II) monosulfide films at different $t_{s}$ were polycrystalline in nature with an orthorhombic structure. It was found that a $30 \mathrm{~min}$ of sulfurization time is sufficient for the formation of single phase SnS. The crystallinity of the sulfurized films initially increased with the increase in $t_{s}$ up to $150 \mathrm{~min}$, and then decreased. The Raman spectra of tin (II) monosulfide films showed modes at 95, 162, 189, 219, and $284 \mathrm{~cm}^{-1}$ for $\mathrm{t}_{\mathrm{S}}<120 \mathrm{~min}$ and 95,189 , and $219 \mathrm{~cm}^{-1}$ for $\mathrm{ts}_{\mathrm{S}} \geq 120 \mathrm{~min}$. Raman modes present at 95,189 , and $219 \mathrm{~cm}^{-1}$ belong to the $\mathrm{Ag}_{\mathrm{g}}$ (strong) mode, and the other modes at 162 and $284 \mathrm{~cm}^{-1}$ belong to the $\mathrm{B}_{2 \mathrm{~g}}$ (weak) mode of SnS. From the transmittance spectra of the sulfurized films, it is clear that the film grown at $30 \mathrm{~min}$ had higher transmittance, and with the increase in $t_{s}$ to $120 \mathrm{~min}$, the transmittance was decreased. The optical bandgap of sulfurized films changed in the range of 1.25-1.50 eV. From the above observations, crystallinity can be improved with the optimization of sulfurization time.

Author Contributions: Conceptualization, V.R.M.R.; methodology, V.R.M.R.; formal analysis, S.G.; investigation, V.R.M.R.; data curation, S.G., R.U.A. and V.R.M.R.; writing-original draft preparation, V.R.M.R.; writing - review and editing, K.T.R.R.; supervision, K.T.R.R.; project administration, K.T.R.R. and C.P.; funding acquisition, K.T.R.R., W.K.K. and C.P. All authors have read and agreed to the published version of the manuscript.

Funding: This research received no external funding.

Institutional Review Board Statement: Not applicable.

Informed Consent Statement: Not applicable.

Data Availability Statement: Data available on request due to restrictions e.g., privacy or ethical.

Acknowledgments: This work was supported by "Human Resources Program in Energy Technology" of the Korea Institute of Energy Technology Evaluation and Planning (KETEP), granted financial resource from the Ministry of Trade, Industry, and Energy, Republic of Korea. (No. 20204010600100).

Conflicts of Interest: The authors declare no conflict of interest. 


\section{References}

1. Kushiya, K. CIS-based thin-film PV technology in solar frontier K.K. Sol. Energy Mater. Sol. Cells 2014, 122, 309-313. [CrossRef]

2. Avrutin, V.; Izyumskaya, N.; Morko, H. Semiconductor solar cells: Recent progress in terrestrial applications. Superlattices Microstruct. 2011, 49, 337-364. [CrossRef]

3. Vasudeva Reddy, M.; Sreedevi, G.; Chinho, P.; Miles, R.W.; Ramakrishna Reddy, K.T. Development of sulphurized SnS thin film solar cells. Curr. Appl. Phys. 2015, 15, 588-598. [CrossRef]

4. Gedi, S.; Reddy, V.R.M.; Park, C.; Chan-Wook, J.; Ramakrishna Reddy, K.T. Comprehensive optical studies on SnS layers synthesized by chemical bath deposition. Opt. Mater. Amst. 2015, 42, 468-475. [CrossRef]

5. Gedi, S.; Minnam Reddy, V.R.; Kotte, T.R.R.; Park, Y.; Kim, W.K. Effect of $\mathrm{C}_{4} \mathrm{H}_{6} \mathrm{O}_{6}$ concentration on the properties of SnS thin films for solar cell applications. Appl. Surf. Sci. 2019, 465, 802-815. [CrossRef]

6. Sreedevi, G.; Vasudeva Reddy, M.; Babu, P.; Chan-Wook, J.; Chinho, P.; Ramakrishna Reddy, K.T. A facile inexpensive route for SnS thin film solar cells with $\mathrm{SnS}_{2}$ buffer. Appl. Surf. Sci. 2016, 372, 116-124. [CrossRef]

7. Vasudeva Reddy, M.; Sreedevi, G.; Babu, P.; Ramakrishna Reddy, K.T.; Guillaume, Z.; Chinho, P. Influence of different substrates on the properties of sulfurized SnS films. Sci. Adv. Mater. 2016, 8, 247-251. [CrossRef]

8. Nwofe, P.A.; Reddy, K.T.R.; Miles, R.W. Influence of Deposition Time on the Properties of Highly-Oriented SnS Thin Films Prepared Using the Thermal Evaporation Method. Adv. Mater. Res. 2012, 602-604, 1409-1412. [CrossRef]

9. Nwofe, P.A.; Reddy, K.T.R.; Miles, R.W. Type conversion of p-SnS to n-SnS using a $\mathrm{SnCl}_{4} \mathrm{CH}_{3} \mathrm{OH}$ heat treatment. In Proceedings of the 2013 IEEE 39th Photovoltaic Specialists Conference, Tampa, FL, USA, 16-21 June 2013; pp. 2518-2523. [CrossRef]

10. Mariappan, R.; Ragavendar, M.; Ponnuswamy, V. Structural and optical characterization of SnS thin films by electro-deposition technique. Opt. Appl. 2011, 41, 989-997.

11. Ricica, T.; Strizik, L.; Dostal, L.; Bouska, M.; Vlcek, M.; Benes, L.; Wagner, T.; Jambor, R. SnS and SnS2 thin films deposited using a spin-coating technique from intramolecularly coordinated organotin sulfides. Appl. Organomet. Chem. 2015, 29, 176-180. [CrossRef]

12. Sajeesh, T.H.; Poornima, N.; Sudha Kartha, C.; Vijayakumar, K.P. Unveiling the defect levels in SnS thin films for photovoltaic applications using photoluminescence technique. Phys. Status Solidi Appl. Mater. Sci. 2010, 207, 1934-1939. [CrossRef]

13. Xie, H.; Sánchez, Y.; López-Marino, S.; Espíndola-Rodríguez, M.; Neuschitzer, M.; Sylla, D.; Fairbrother, A.; Izquierdo-Roca, V.; Pérez-Rodríguez, A.; Saucedo, E. Impact of Sn (S, Se) Secondary Phases in Cu2ZnSn(S, Se)4 Solar Cells: A Chemical Route for Their Selective Removal and Absorber Surface Passivation. ACS Appl. Mater. Interfaces 2014, 6, 12744-12751. [CrossRef]

14. Sinsermsuksakul, P.; Sun, L.; Lee, S.W.; Park, H.H.; Kim, S.B.; Yang, C.; Gordon, R.G. Overcoming Efficiency Limitations of SnS-Based Solar Cells. Adv. Energy Mater. 2014, 4, 1400496. [CrossRef]

15. Schneikart, A.; Schimper, H.J.; Klein, A.; Jaegermann, W. Efficiency limitations of thermally evaporated thin-film SnS solar cells. J. Phys. D. Appl. Phys. 2013, 46. [CrossRef]

16. Banai, R.E.; Horn, M.W.; Brownson, J.R.S. A review of tin (II) monosulfide and its potential as a photovoltaic absorber. Sol. Energy Mater. Sol. Cells 2016, 150, 112-129. [CrossRef]

17. Minnam Reddy, V.R.; Lindwall, G.; Pejjai, B.; Gedi, S.; Kotte, T.R.R.; Sugiyama, M.; Liu, Z.K.; Chinho, P. $\alpha$-SnSe thin film solar cells produced by selenization of magnetron sputtered tin precursors. Sol. Energy Mater. Sol. Cells 2018, 176, 251-258. [CrossRef]

18. Ahmet, I.Y.; Hill, M.S.; Johnson, A.L.; Peter, L.M. Polymorph-Selective Deposition of High Purity SnS Thin Films from a Single Source Precursor. Chem. Mater. 2015, 27, 7680-7688. [CrossRef]

19. Joshi, M.P.; Khot, K.V.; Patil, S.S.; Mali, S.S.; Hong, C.K.; Bhosale, P.N. Investigating the light harvesting capacity of sulfur ion concentration dependent SnS 2 thin films synthesized by self-assembled arrested precipitation technique. Mater. Res. Express 2019, 6, 086467. [CrossRef]

20. Calderón Triana, C.L.; Banguero, E.; Bartolo-Pérez, P.; Gordillo, G. Preparation and Characterization of SnS:Bi Thin Films. Braz. J. Phys. 2011, 41, 15-20. [CrossRef]

21. Jing, L.; Xu, Y.; Zhang, M.; Xie, M.; Xu, H.; He, M.; Liu, J.; Huang, S.; Li, H. Novel Ag2S quantum dot modified 3D flower-like SnS2 composites for photocatalytic and photoelectrochemical applications. Inorg. Chem. Front. 2018, 5, 63-72. [CrossRef]

22. Jiang, F.; Shen, H.; Gao, C.; Liu, B.; Lin, L.; Shen, Z. Preparation and properties of SnS film grown by two-stage process. Appl. Surf. Sci. 2011, 257, 4901-4905. [CrossRef]

23. Sinsermsuksakul, P.; Heo, J.; Noh, W.; Hock, A.S.; Gordon, R.G. Atomic layer deposition of tin monosulfide thin films. Adv. Energy Mater. 2011, 1, 1116-1125. [CrossRef]

24. Tanusevski, A. Optical and photoelectric properties of SnS thin films prepared by chemical bath deposition. Semicond. Sci. Technol. 2003, 18, 501-505. [CrossRef]

25. Cheng, S.; He, Y.; Chen, G.; Cho, E.C.; Conibeer, G. Influence of EDTA concentration on the structure and properties of SnS films prepared by electrodeposition. Surf. Coat. Technol. 2008, 202, 6070-6074. [CrossRef]

26. Chaki, S.H.; Deshpande, M.P.; Trivedi, D.P.; Tailor, J.P.; Chaudhary, M.D.; Mahato, K. Wet chemical synthesis and characterization of SnS2 nanoparticles. Appl. Nanosci. 2013, 3, 189-195. [CrossRef]

27. Lu, F.Y.; Yang, J.H.; Li, R.X.; Huo, N.J.; Li, Y.T.; Wei, Z.M.; Li, J.B. Gas-dependent photoresponse of SnS nanoparticles-based photodetectors. J. Mater. Chem. C 2015, 3, 1397-1402. [CrossRef]

28. Banu, S.; Ahn, S.J.; Eo, Y.J.; Gwak, J.; Cho, A. Tin monosulfide (SnS) thin films grown by liquid-phase deposition. Sol. Energy 2017, 145, 33-41. [CrossRef] 